\title{
Relative role of pre-monsoon conditions and intraseasonal oscillations in determining early-vs-late indian monsoon intensity in a GCM
}

\author{
Rohit Ghosh $^{1,3}$ - Arindam Chakraborty ${ }^{1,2}$ - Ravi S Nanjundiah ${ }^{1,2}$
}

Received: 18 February 2016 / Accepted: 8 October 2016 / Published online: 27 October 2016

(C) The Author(s) 2016. This article is published with open access at Springerlink.com

\begin{abstract}
The aim of this paper is to identify relative roles of different land-atmospheric conditions, apart from sea surface temperature (SST), in determining early vs. late summer monsoon intensity over India in a high resolution general circulation model (GCM). We find that in its early phase (June-July; JJ), pre-monsoon land-atmospheric processes play major role to modulate the precipitation over Indian region. These effects of pre-monsoon conditions decrease substantially during its later phase (August-September; AS) for which the interannual variation is mainly governed by the low frequency northward propagating intraseasonal oscillations. This intraseasonal variability which is related to mean vertical wind shear has a significant role during the early phase of monsoon as well. Further, using multiple linear regression, we show that interannual variation of early and late monsoon rainfall over India is best explained when all these land-atmospheric parameters are taken together. Our study delineates the relative role of different processes
\end{abstract}

Rohit Ghosh

rohit.ghosh@mpimet.mpg.de

Arindam Chakraborty

arch@caos.iisc.ernet.in

Ravi S Nanjundiah

ravi@caos.iisc.ernet.in

1 Centre for Atmospheric and Oceanic Sciences,

Indian Institute of Science, Bengaluru, India

2 Divecha Centre for Climate Change,

Indian Institute of Science, Bengaluru, India

3 Present address: International Max Planck Research School on Earth System Modelling,

Max Planck Institute for Meteorology, Hamburg, Germany affecting early versus later summer monsoon rainfall over India that can be used for determining its subseasonal predictability.

\section{Introduction}

Summer monsoon precipitation plays a major role in the economics of the Indian subcontinent (Gadgil et al. 2004) where agriculture is the vital source of growth. However, an accurate prediction of the interannual variations of Indian Summer (June-September: JJAS) Monsoon Rainfall (ISMR) at least a season in advance remains challenging. It is more difficult to predict the extremes of monsoon precipitation-the most important aspect of interannual variation (Webster et al. 1998). The poor predictability of the seasonal mean ISMR could be due to the fact that the unpredictable internal dynamics plays a major role in determining its interannual variation.

Interannual variation of sea surface temperature (SST) is considered as the primary forcing modulating the interannual variation of monsoon over India (Goswami 1998). Several studies show that there is a link between El-Niño and Southern Oscillation (ENSO) and the intensity of ISMR (e.g., Pant and Parthasarathy, 1981; Sikka, 1980; Rasmusson and Carpenter, 1983). Droughts are more probable during the warmer east Pacific SST phase (El-Niño). On the other hand, excess rainfall is more probable during the cooler phase of eastern Pacific SST (La-Niña). However, a strong monsoon-ENSO relationship came under doubt after some striking failures of the proposed linkage (e.g., during 1994, 1997 summer monsoon). Kumar et al. (1999) claimed that the relationship had been weakening since the last two decades. Moreover, there is an equal chance of having deficit and excess rainfall with El-Niño (Kumar et al. 2006; 
Gadgil et al. 2007). In the last decade, another link was found related to SST variations in Equatorial Indian Ocean (EIO) which is termed as Equatorial Indian Ocean Oscillation (EQUINOO; Gadgil et al. 2004). It was shown that ENSO and EQUINOO together can explain more extremes of ISMR as compared to ENSO alone. However, all the factors related to SST can explain at most $50 \%$ of the variability in monsoon rainfall (Goswami and Xavier 2005). Hence, there could be many other reasons which are governing the rest of the $50 \%$ of monsoon variability.

Other than the impact of SST, there are pre-monsoon land-atmosphere processes which can play vital role in determining the interannual variation of monsoon over the Indian region. The Eurasian Snow cover is one of the most well-known among them (Barnett et al. 1989; Vernekar and Zhou 1995; Fasullo 2004; Ye and Bao 2005; Peings and Douville 2010). The pre-monsoon soil moisture (SM) is supposed to have an impact over the monsoon rainfall too (Shukla and Mintz 1982; Douville et al. 2001; Douville 2002; Eltahir 1998; Fennessy and Shukla 1999). Joseph and Srinivasan (1999) have shown that the $200 \mathrm{hPa}$ meridional wind anomaly in May has a very prominent impact over the monsoon rainfall. The pre-monsoon surface moist static energy (MSE) also has relation with the upcoming monsoon rainfall (Chakraborty et al. 2006, 2014). However, a comprehensive study examining the relative impacts of these land-atmosphere parameters in determining summer monsoon over India in absence of interannual variations of SST forcing has not been reported so far. Therefore, it is necessary to separate the impact of interannual variation of SST from other parameters to understand the relative role of the later in determining interannual variation of ISMR. Such a study is possible using a general circulation model (GCM) forced by SST that does not vary interannually.

The seasonal mean of ISMR depends on its relative intensity during early (June-July: JJ; climatological contribution $52 \%$ ) and late (August-September: AS; climatological contribution $48 \%$ ) phases. However, it has been shown by Terray et al. (2003) that the early and late ISMR intensities are uncorrelated, and it might be associated with the evolution of ENSO (Boschat et al. 2011, 2012). The non-existing relationship between the anomalies of early and late Indian summer monsoon could also be related to the fact that premonsoon conditions like the SM are more likely to impact the early part of the season (Saha et al. 2010) as compared to the later part when, after the onset, the internal dynamics is more likely to play a major role. Such changes in the dependence of monsoon rainfall on land-atmospheric conditions can have profound influence on the predictability of longrange as well as short- to medium-range forecasts which shows different rates of error growth over land as compared to the ocean (Chakraborty 2010).
In this paper, we try to understand the relative role played by different important land-atmosphere parameters in determining the early and late ISMR intensities using a high resolution global GCM. We force the model with seasonally varying climatological SST conditions to eliminate the impact of the interannual variation of SST on monsoon rainfall. A brief description of the model used is given in Section 2. The experimental details are provided in Section 3, and the results are discussed in Section 4. Section 5 illustrates the use of a Multiple Linear Regression to find relative impacts of different parameters on Indian monsoon, followed by the summary and conclusions of the study.

\section{Model description}

The atmospheric component of CCSM4 (Community Climate System Model 4) (Gent et al. 2011), the Community Atmospheric Model 4.0 (CAM4) (Neale et al. 2011), developed by National Center for Atmospheric Research (NCAR) is used for this study. The model has a finite volume dynamical core (Lin 2004). The horizontal grid has $384 \times 576$ latitude/longitude divisions resulting in a high resolution of $0.45^{\circ}$ latitude and $0.625^{\circ}$ longitude spacing over the globe. The mass flux scheme by Zhang and McFarlane (1995) is used for deep convection parameterization. The shallow convection scheme by Hack (1994) is used in the model. The model has 26 vertical layers.

\section{Experimental details}

We perform a 50-year long simulation of the model. The boundary conditions over the ocean (SST) are forced from the climatological monthly mean values of Hadley Centre which is constructed by the Met Office Hadley Centre for Climate Prediction and Research (Rayner et al. 2003). Therefore, the model saw seasonally varying SST. However these values do not change from year to year. The CAM4 is coupled to a land surface model (CLM4) (Lawrence et al. 2011a) which allows it to interact with the atmospheric model throughout the simulation.

For the observational analysis, precipitation data from three different sources are used. Those are the Climate Prediction Center Merged Analysis of Precipitation (CMAP) data (Xie and Arkin 1996) for the period of 1979 to 2015 at $2.5^{\circ} \times 2.5^{\circ}$ resolution, the Indian Meteorological Department (IMD) monthly mean precipitation data (1971-2009) at $1^{\circ} \times 1^{\circ}$ resolution (Rajeevan et al. 2006) and the TRMM (Tropical Rainfall Measurement Mission) 3B43 monthly mean precipitation data for the period 1998 to 2015 at 
$0.25^{\circ} \times 0.25^{\circ}$ resolution (Huffman et al. 2007). The ERA 40 zonal wind data for 200 and $850 \mathrm{hPa}$ are used as observational estimates of zonal wind during the analysis (Uppala et al. 2005).

Correlation is used extensively during the analysis of the data. Hence, we mention that any correlation value above 0.28 can be considered statistically significant at $95 \%$ level according to the two sided student $t$ test for our sample size of 50 years.

\section{Results}

Figure 1 shows summer (June-September) precipitation climatology over south and east Asia from observational estimates of CMAP (1979-2015), TRMM (1998-2015), and the model simulation (50 years). The model is able to capture the high precipitation zones along the west coast of Indian peninsular, over northern Bay of Bengal, foot hills of the Himalayas and over the EIO. However, the intensity of precipitation to the west of the Western Ghats is higher compared to the CMAP estimates. This could be on account of high resolution of the model $(\sim 0.5 \times 0.5$ degree $)$ which is essential for capturing orographic precipitation along narrow mountains like the Western Ghats when compared to CMAP $(2.5 \times 2.5$ degree $)$. The proof of that is the close correspondence of the model climatological precipitation with the high resolution TRMM $(0.25 \times 0.25$ degree $)$ climatology over the Western Ghats. We also note that precipitation over the head Bay of Bengal is spread over a larger region with reduced intensity as compared to CMAP. Orographic precipitation south of the Himalayas in the model is closer to the TRMM precipitation. These features are similar to that when CAM4 was forced with interannual varying SST (Meehl et al. 2012). It is noticeable that the model is unable
Climatological Precipitation, Indian Region, JJAS

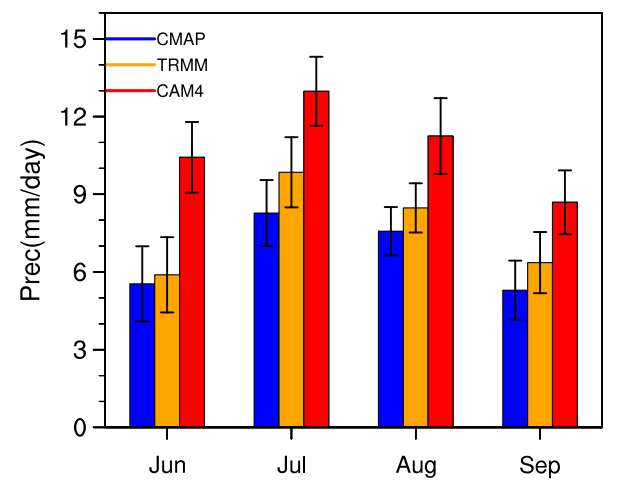

Fig. 2 Monthly mean climatology of precipitation from June through September over the Indian region $\left(70^{\circ}-90^{\circ} \mathrm{E}, 8^{\circ}-28^{\circ} \mathrm{N}\right.$, land part) from CMAP estimates (1979-2015), TRMM (1998-2015) and 50year simulations of CAM4. The black vertical straight line at the top of the bars represent one standard deviation

to produce the observed convection center over the Eastern equatorial Indian Ocean which is also apparent when the model is forced with observed SST (Islam et al. 2013). However, altogether, the model simulated a reasonable spatial pattern of summer precipitation climatology over the Indian subcontinent when compared to the observational estimates. The pattern correlation of the model climatology over the region $70^{\circ}-90^{\circ} \mathrm{E}, 8^{\circ}-28^{\circ} \mathrm{N}$ (will be termed as Indian region in this paper) with the CMAP estimate and TRMM (Fig. 1) are 0.44 and 0.64, respectively, which clearly shows the improvement of observed estimates of precipitation pattern with increase in resolution.

Variations within the season averaged over the Indian region (land part) is shown in Fig. 2. Highest precipitation in July and lowest precipitation in September (within the 4 months of the monsoon season), seen in the model simulation are similar to that in the CMAP estimates and TRMM.

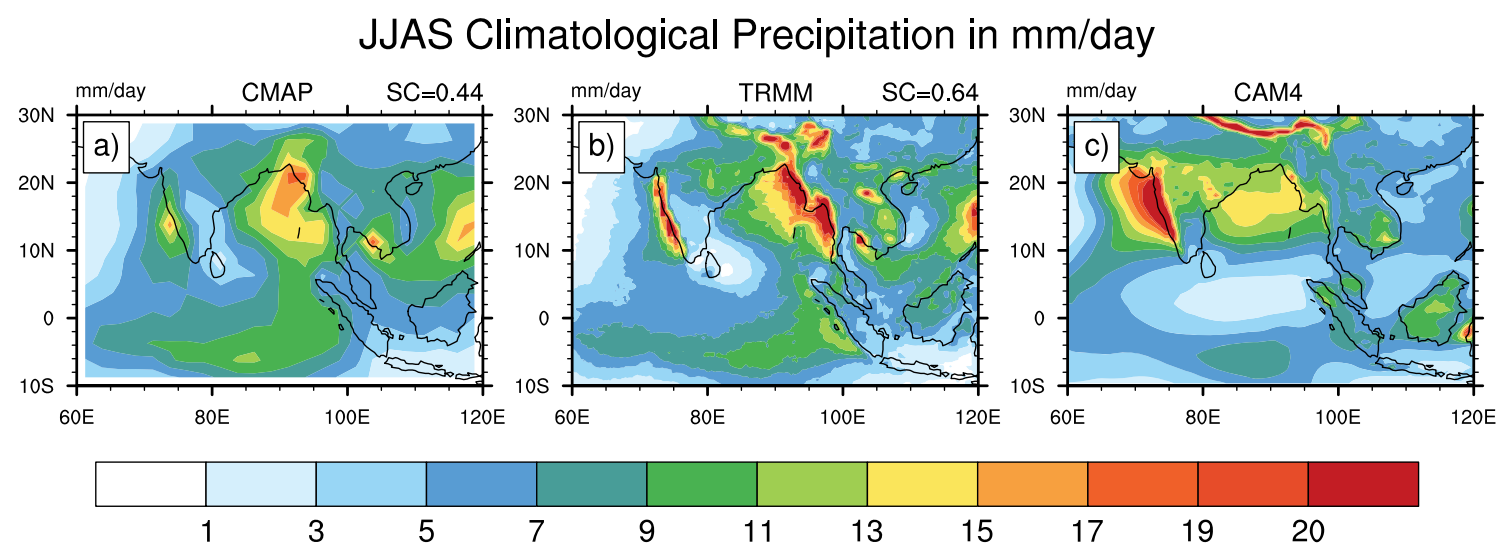

Fig. 1 Climatological precipitation from a CMAP estimates (19792015), b TRMM (1998-2015) and c 50-year CAM4 simulation with seasonally varying climatological SST forcing. The spatial correlation

(SC) of the CAM4 climatology patterns with CMAP estimates and TRMM, over the Indian region $\left(70^{\circ}-90^{\circ} \mathrm{E}, 8^{\circ}-28^{\circ} \mathrm{N}\right)$, is shown as number at the top of the left and middle panel respectively 
Albeit an overestimation, therefore, the sub-seasonal cycle is well simulated by the model.

\subsection{Interannual variation}

Noting, in the previous section, that the spatial pattern of the precipitation climatology and its sub-seasonal variation over Indian region are reasonably captured by the CAM4 model vis-a-vis CMAP observations, it is necessary to see if the model (forced by climatological SST) shows any significant interannual variation. Such variation in normalised ISMR for 50-years is illustrated in Fig. 3. On the time axis, the numbers are the corresponding years from when the model simulation started and do not directly correspond to any calendar year due to the nature of SST forcing (seasonally varying climatological). Despite the fact that SST does not vary from 1 year to other, there are large interannual variations in simulated precipitation over the Indian region. This result is consistent with the previous studies (Goswami and Xavier 2005; Krishnan et al. 2009; Saha et al. 2010). The 50-year mean ISMR is $10.8 \mathrm{~mm} \mathrm{day}^{-1}$ and its interannual standard deviation is 0.72 . The ratio of model standard deviation to its mean $(7 \%)$ is smaller compared to that observed $(\sim 10 \%)$. This could mainly be due to the fact that SST did not vary from year-to-year which is known to be the primary forcing for boreal summer monsoon interannual variation. There are 8 years $(4,6,10,20,24,31,34$, and 46) with seasonal mean precipitation anomaly below -1 standard deviation. We term these drought years of the model. Similarly, there are 8 years $(22,28,29,36,37,42,49$, and 50) with ISMR anomaly above 1 standard deviation. These are termed as flood years. We next compare the spatial precipitation pattern during the extreme years as compared to the observational estimate.

\subsection{Anomaly during extreme years}

Figure 4 shows the composite anomaly patterns of precipitation during June-September from the model simulation and observational estimates of IMD and CMAP. The composites from the model are based on 8 drought years and 8 flood years occurred during the 50-year run. The composites for CMAP are calculated based on the 6 drought years (1979, 1982, 1987, 2002, 2009, and 2014) and 3 flood years (1983, 1988, and 1994) appeared between 1979 to 2009. Due to the longer data period, IMD composites comprise another flood year (1975) and two additional drought years (1972 and 1974).

In observations, the spatial pattern of anomaly during flood and drought years are coherent over the entire south Asia including Bay of Bengal. However, north-east Indian region shows opposite signs of anomaly during flood years in the composite pattern. There is an east-west dipole of anomaly along EIO in observations. This could be related to the Indian Ocean Dipole (IOD) and EQUINOO. However, the model simulated anomalies are coherent in eastwest over the equatorial Indian Ocean. This could be related to the fact that the model was not forced by interannual variation SST that eliminates the east-west dipole pattern.

\subsection{Anomalies during June-July and August-September}

Are those anomalies in precipitation in the model seen in Figs. 3 and 4 coherent within the season? From observations, it is known that precipitation anomalies over Indian region during the beginning of the monsoon season $(\mathrm{JJ})$ are different than that at the end of the season (AS). This could be due to the fact that pre-monsoon land surface conditions
Fig. 3 Normalised anomaly of precipitation over the Indian region $\left(70^{\circ}-90^{\circ} \mathrm{E}, 8^{\circ}-28^{\circ} \mathrm{N}\right.$, land part) in June-September during 50 years of CAM4 simulation with seasonally varying climatological SST forcing

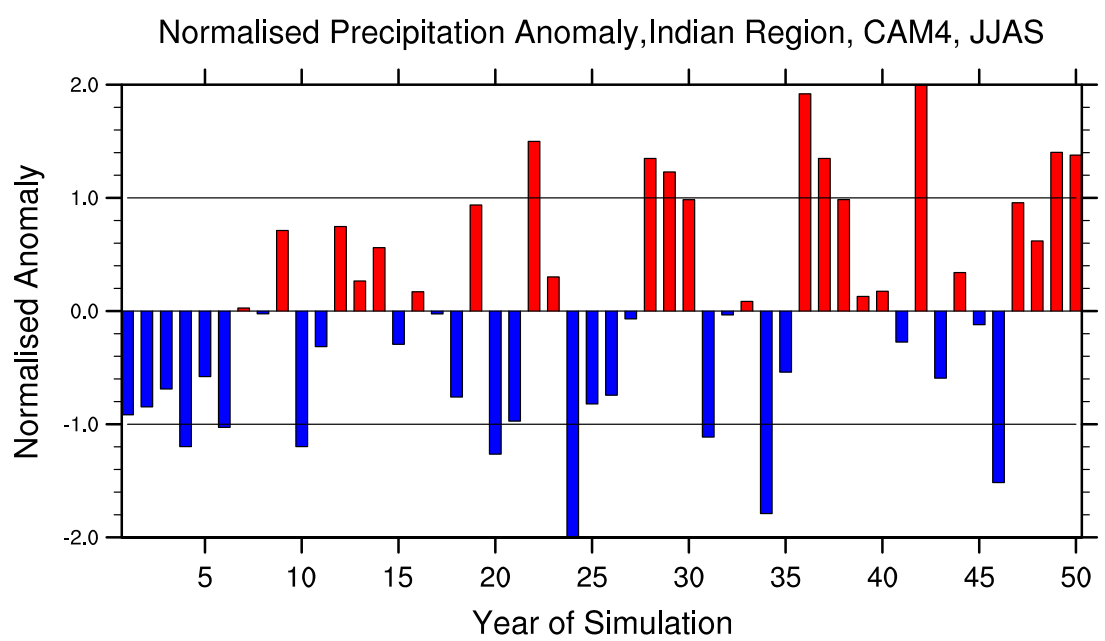


play significant role in its early parts (Saha et al. 2010). However, once onset (all-over Indian region) is established, the conditions change due to feedback and precipitation anomalies during later part of the season becomes independent of the pre-monsoon conditions (Chakraborty et al. 2006).

Figure 5 further supports the studies mentioned above. We note that there is no robust relation between JJ and AS rainfall anomaly over the Indian region in the model. For example, there are years (like 16, 12 and 42) when the JJ and AS anomalies are of opposite sign with large magnitude at least in one of those two parts of the season. The correlation between JJ and AS anomalies in the model is 0.13 . Figure $5 \mathrm{~b}$ shows corresponding statistics from observational estimates of CMAP during 1979-2015. There are years like 1984, 1991, and 1998 when anomalies during JJ and AS have large values with opposite sign. The correlation between these two pairs of months in CMAP estimates is 0.09 .

The above result indicates that the early (JJ) and the late (AS) phases of summer monsoon are possibly controlled by different mechanisms. Previous studies suggest that pre-monsoon conditions playing major role in the early parts of the monsoon compared to its later parts (e.g., Rai et al. 2015). Several pre-onset land-atmospheric parameters are shown to have impact during the monsoon. Based on previous studies, we identify the following parameters for further analysis in this paper: soil moisture (Rai et al. 2015), near surface moist static energy (Chakraborty et al. 2006), Eurasian snow cover (Douglas and Shukla 1976), and phase of upper tropospheric Rossby waves (Joseph and Srinivasan 1999). However, from previous studies, the relative importance of these parameters in early (JJ) and late (AS) phases of monsoon is not clear. In the following section, we
Fig. 4 Composite anomaly of precipitation in IMD-based observations (top panels), CMAP estimates (middle panels), and CAM4 simulation (bottom panels) during flood years (left panels) and drought years (right panels). The hatched regions shown in panels $c$ and $f$ are the regions where the rainfall is significantly different from the climatological mean at $95 \%$ significance level
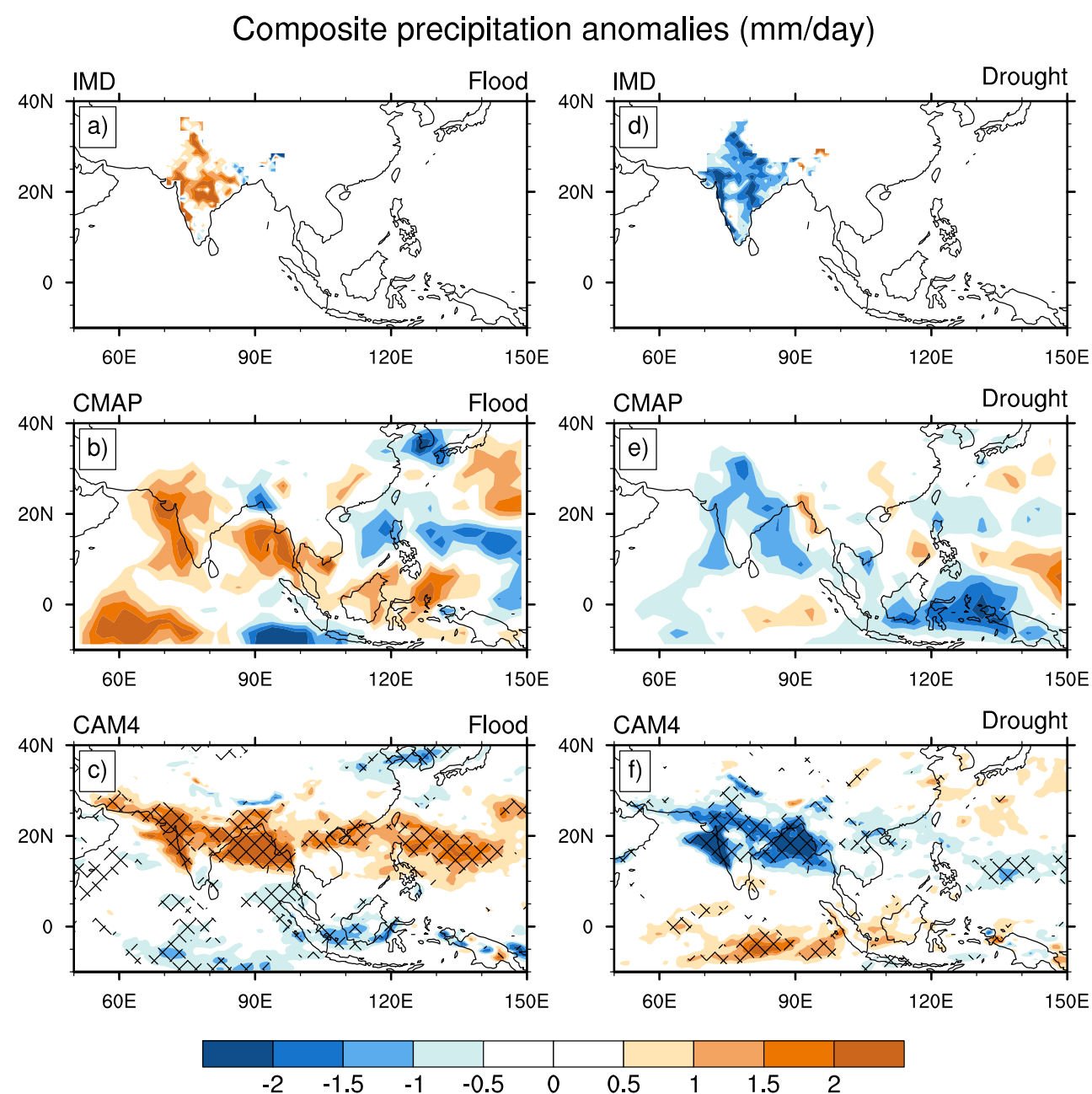


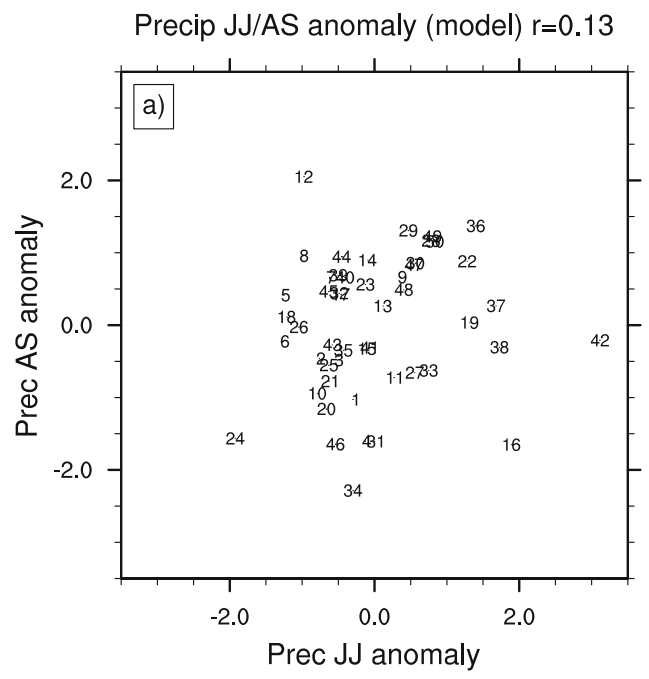

Fig. 5 Relationship between anomaly of precipitation in June-July and August-September over Indian region $\left(70^{\circ}-90^{\circ} \mathrm{E}, 8^{\circ}-28^{\circ} \mathrm{N}\right.$, land part) in a 50-year CAM4 simulation and $\mathbf{b}$ CMAP estimates. Two digit

investigate the role of these land-atmosphere conditions during $\mathrm{JJ}$ and AS separately.

\section{Pre-monsoon conditions controlling early and late phases of monsoon precipitation}

\subsection{Moist static energy}

It was shown by several previous studies that the MSE and vertical moist-static stability (VMS) of the atmosphere play pivotal role in determining the intensity of convection (Neelin and Held 1987; Zhang 1994; Nanjundiah 2000; Rajagopalan and Molnar 2013). The surface MSE just before the onset of monsoon is one of the precursory measures for the subsequent monsoon season (Chakraborty et al. 2006). The MSE is defined as

$M S E=C_{p} T+L q+g z$

where $C_{p}$ is specific heat of dry air at constant pressure, $L$ is latent heat of evaporation, $g$ is gravitational acceleration, $T$

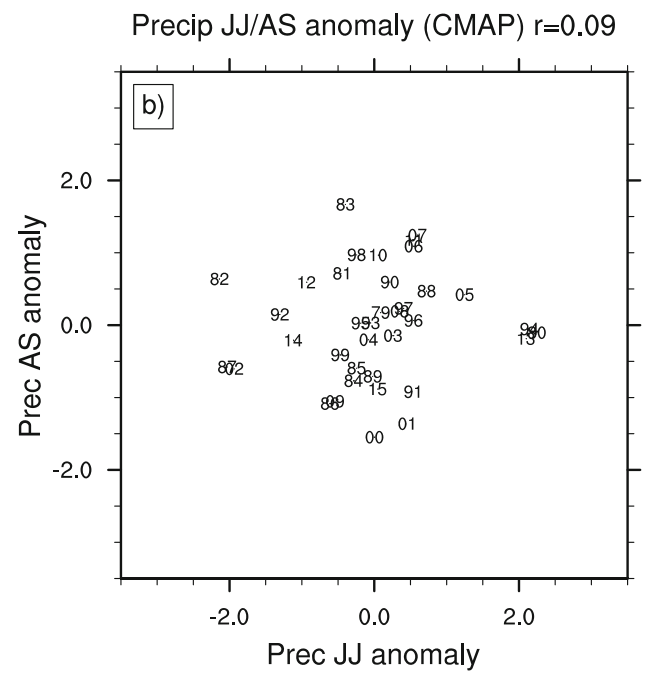

year numbers of model simulation and last two digits of calendar year for observations are marked in this figure

is temperature, $q$ is specific humidity, and $z$ the geopotential height.

Figure 6a shows the spatial correlation of MSE at 2meter above surface in May with the June-July rainfall averaged over the Indian region for the 50-years of model simulation. It suggests a positive relationship between premonsoon MSE and JJ precipitation over the Indian region. The strongest relation comes over northern parts of peninsular India. Figure 6 shows the same with the AS rainfall averaged over India. The relation between MSE and ISMR has weakened from the corresponding JJ values, except that over western parts of the peninsular India. This could be due to the fact that the effect of MSE in May have greater effect with a smaller lead time (JJ) as compared to AS.

\subsection{Soil moisture}

Pre-monsoon soil moisture is another parameter which can govern the intensity of monsoon rainfall over India (Shukla and Mintz 1982; Douville et al. 2001; Eltahir 1998). Soil moisture has a positive feedback on rainfall. Higher the soil
Fig. 6 Temporal correlation of interannual variations of surface MSE in May at every grid with precipitation over Indian region during a June-July and b August-September. The correlation in the shaded dot region are $95 \%$ significant according to student $t$ test

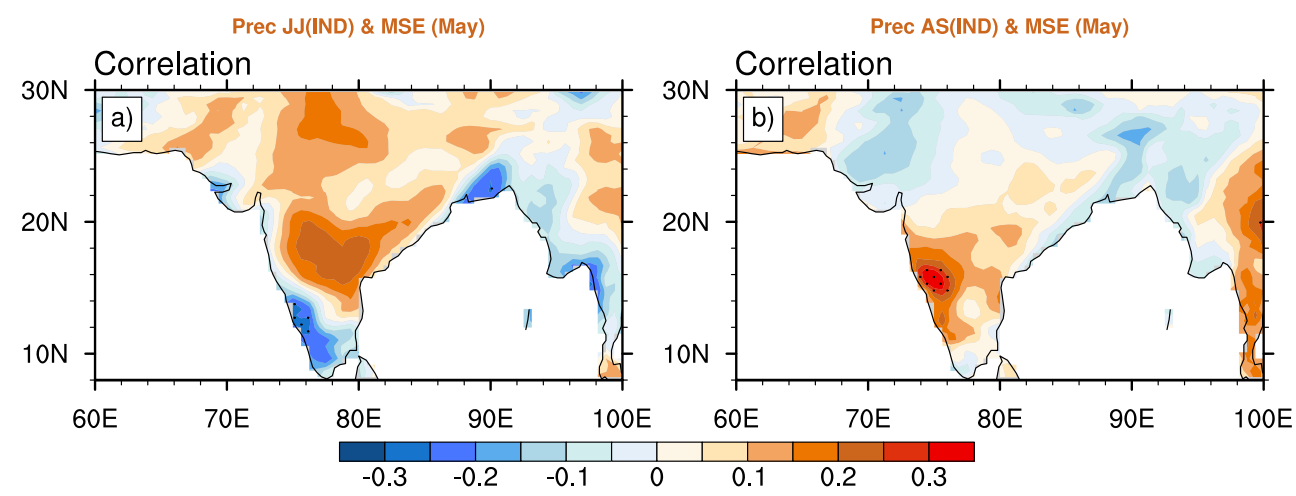


Fig. 7 Temporal correlation of interannual variations of moisture content of top $10 \mathrm{~cm}$ of the soil in May at every grid with precipitation over Indian region during a June-July and $\mathbf{b}$ August-September. The correlation in the shaded dot region are $95 \%$ significant according to student $t$ test

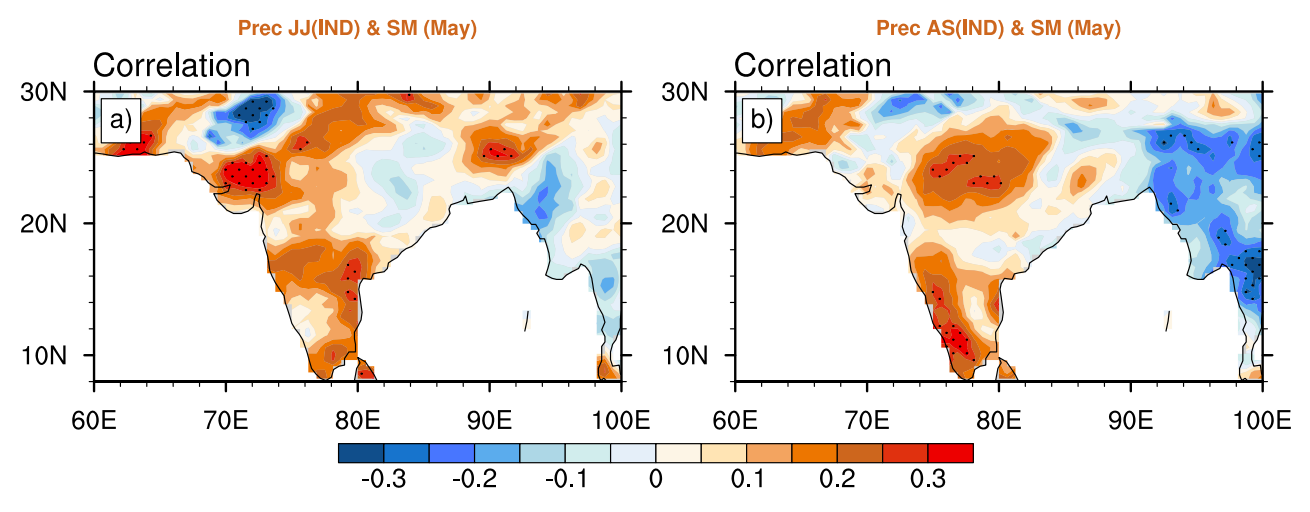

moisture higher the evaporation and it eventually reduces the height of the Planetary Boundary Layer (PBL) over that region leading to a more favourable condition for precipitation. Figure 7 a shows the correlation of precipitation averaged over the Indian region in JJ with the soil moisture of the upper $10 \mathrm{~cm}$ layer of soil in May at every grid in 50-year model simulation. This figure shows a positive relationship between pre-monsoon SM and early monsoon precipitation. The correlation is stronger over the western parts of India and the southern India. This suggests a positive feed back between the advancement of monsoon onset isocrones and the soil moisture as pointed out by (Krishnamurti et al. 2012). According to that, wet (dry) land surface conditions before onset will help (restrict) the advancement of convective systems over land. Unlike that for surface MSE (Fig. 6), pre-monsoon SM has almost equal impact on precipitation during AS (Fig. 7b). However, the region of highest correlation in AS shifts to central India and western parts of Indian peninsula.

\subsection{Eurasian snow depth}

Previous researches suggest that Eurasian snow cover in the winter as well as in spring has an impact on subsequent monsoon precipitaiton (Douglas and Shukla 1976; Vernekar and Zhou 1995; Bamzai and Shukla 1999). In winter or spring, most of the Eurasian region is covered with snow but the depth of the snow varies from year to year. As a consequence, the heat required to melt the snow varies from year-to-year which affects the vertical temperature gradient that influences the monsoon trough for its advancement towards the Indian region. Altogether, the previous researches suggested a negative relation between monsoon and snow depth over Eurasia. Figure 8 shows correlation of interannual variations of snow depth over northern Europe and Asia during March (representing spring) with precipitation over Indian region in the 50-year model simulation. Figure 8 a shows regions with strongest negative relationship over Eurasia $\left(60^{\circ}-80^{\circ} \mathrm{E}\right)$ and eastern Asia $\left(120^{\circ}-140^{\circ} \mathrm{E}\right)$ in JJ. However, the correlation is not significant at $95 \%$ level over the Eurasian region where previous researches found a link with the ISMR. Moreover, there is mixed response over the Eurasian continent with prominent negative as well as positive correlations. Therefore, the proposed monsoon link with the Eurasian snow seems very weak in the model. A similar correlation pattern with AS precipitation over Indian region shows no strong negative correlation over Eurasia. This indicates that the Eurasian snow depth in Spring may slightly influence the early summer monsoon (JJ) compared to the later part (AS).

\subsection{Upper tropospheric rossby wave}

It has been shown by Joseph and Srinivasan (1999) that a spatial shift in $200 \mathrm{hPa}$ Rossby wave over south Asia in May can have a large impact on the subsequent monsoon
Fig. 8 Temporal correlation of interannual variations of snow depth in March at every grid with precipitation over Indian region during a June-July and $\mathbf{b}$ August-September. The correlation in the shaded dot region are $95 \%$ significant according to student $t$ test

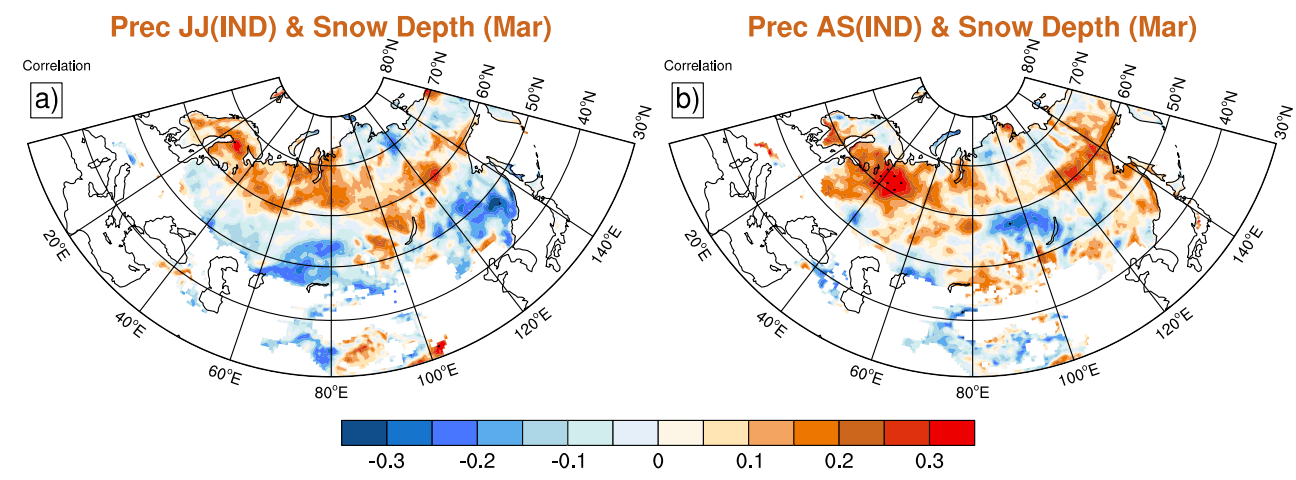




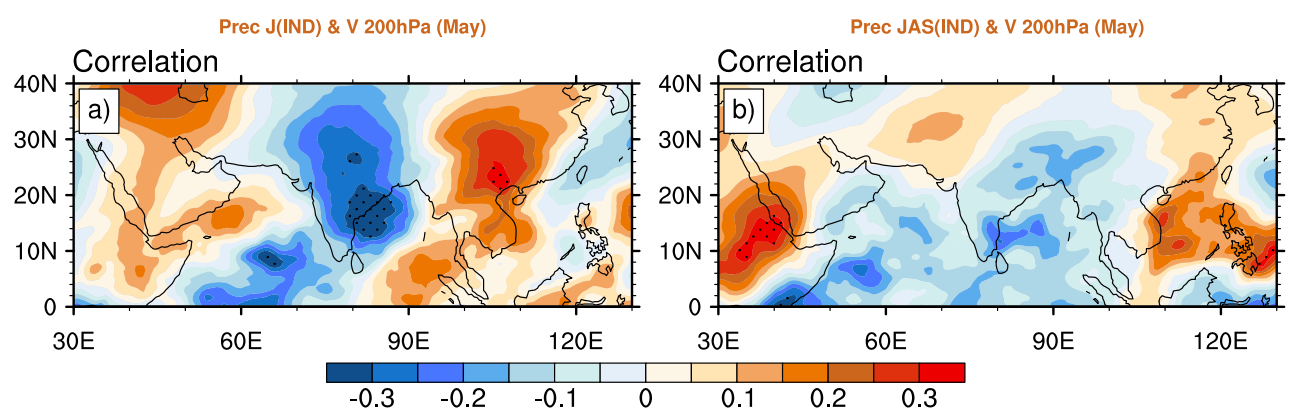

Fig. 9 Temporal correlation of interannual variations of meridional wind at $200 \mathrm{hPa}$ in May at every grid with precipitation over Indian region during a June-July and b August-September. The correlation in the shaded dot region are $95 \%$ significant according to student $t$ test

precipitation. According to their study, when $200 \mathrm{hPa}$ meridional wind anomaly in May is negative (positive) over Indian region, the possibility of having a good monsoon is higher (less). Figure 9 shows correlation of interannual variations of meridional wind at $200 \mathrm{hPa}$ during May at every grid point with the June-September mean precipitation over Indian region in the 50-year model simulation. The positive and negative correlation patches seen in this figure are similar to that mentioned in Joseph and Srinivasan (1999). The impact reduces in August-September over the Indian region. Therefore, all the factors discussed so far have more effect on the intial phase of the monsoon (JJ) than the later (AS). Hence, there must be some other reason which is mainly affecting the end phase of the monsoon rainfall over the Indian region.

\section{Role of equatorial Indian ocean}

It has been seen in Fig. 4 that precipitation anomalies assume opposite signs north and south of around $10^{\circ} \mathrm{N}$ over south Asia in the model simulation as well as in CMAP estimates. This see-saw pattern in anomalous precipitation is more evident in Fig. 10. This figure shows correlation of interannual precipitation over each grid point to that averaged over Indian region in June-July (left panel) and AugustSeptember (AS) separately. During June-July (left panel), strongest positive correlation is found over central India and Bay of Bengal. This is consistent with the fact that inter-tropical convergence zone (ITCZ) is usually coherent over these regions on interannual time scale. It can also be noticed that the positive correlation band extends eastward on to western Pacific Ocean up to about $150^{\circ}$ E. On the other hand, a strong negative correlation of precipitation over south of $10^{\circ} \mathrm{N}$ and Indian region is seen in this figure. This negative correlation pattern extends from over Arabian Sea up to west Pacific Ocean and has the same longitudinal dimension as the positive correlation band. This result suggests a large scale see-saw of ITCZ between equator and northern parts of south-east Asia in the absence of interannual variations of SST. The spatial pattern of this correlation is stronger in August-September (Fig. 10b) as compared to June-July. Therefore, this precipitation see-saw response is playing the main role during the later phase of the monsoon. These results motivate us to investigate the combined effect of the factors which have relative role on the monsoon over Indian region in its two distinct phases.

\section{Relative contributions of land-atmospheric conditions}

It is evident from above discussion that several factors play role in determining the summer monsoon precipitation during the two phases over India and east Asia with climatological SST forcing. On this note, we have tried to calculate the relative importance of these parameters on June-September precipitation over Indian region. We have used multiple
Fig. 10 Temporal correlation of interannual variations of precipitation at every grid with precipitation averaged over Indian region during (a) JuneJuly and (b) August-September. The correlation in the shaded (dot) region are $95 \%$ significant according to student-t test

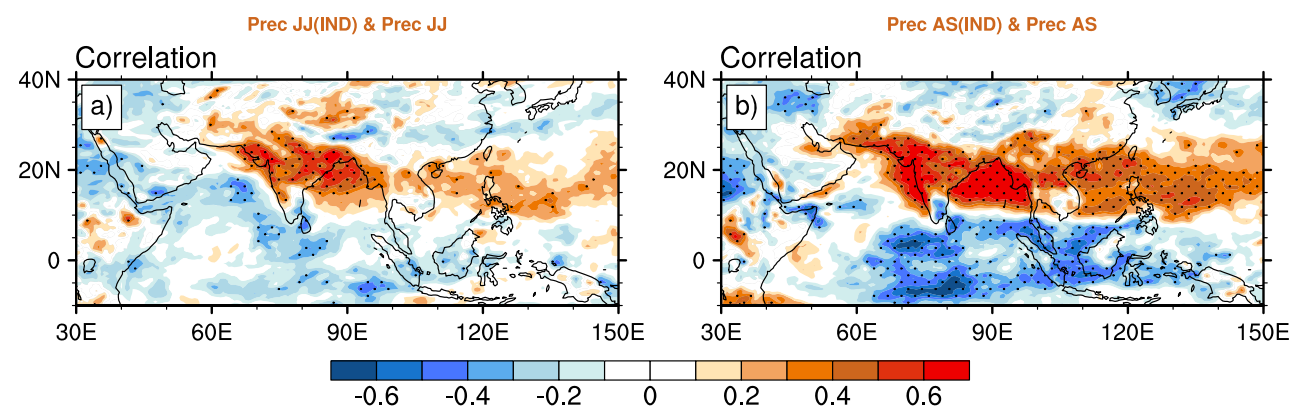


Table 1 Inter-correlation of MSE in May, SM in May, V $200 \mathrm{hPa}$ in May averaged over Indian region $\left(70^{\circ}-90^{\circ} \mathrm{E}, 8^{\circ}-28^{\circ} \mathrm{N}\right)$ and $\mathrm{SD}$ in March over $50^{\circ}-55^{\circ} \mathrm{N}$ and $60^{\circ}-80^{\circ} \mathrm{E}$

\begin{tabular}{lllll}
\hline Parameters & MSE & SM & SD & V \\
\hline SM & 0.82 & & & \\
SD & -0.03 & -0.06 & & \\
V & -0.45 & -0.2 & 0.08 & \\
EIO(JJ) & 0.06 & -0.09 & 0.01 & -0.1 \\
EIO(AS) & 0 & -0.22 & 0 & -0.04 \\
EIO(JJAS) & 0.03 & -0.22 & 0.01 & -0.08 \\
\hline
\end{tabular}

Additionally, the the correlation of EIO averaged precipitation in JJ, AS, and JJAS with the four precursory parameters are also shown. The correlation values in bold are significant at $95 \%$ level

linear regression (MLR) for this purpose. According to this method, precipitation averaged over Indian region can be expressed as a function of five parameters discussed above. Among these five parameters, for MSE, SM, and V $200 \mathrm{hPa}$ in May, the Indian region $\left(70^{\circ}-90^{\circ} \mathrm{E}, 8^{\circ}-28^{\circ} \mathrm{N}\right)$ is chosen for the MLR. For equatorial Indian Ocean (EIO), the precipitation is averaged over $55^{\circ}-95^{\circ} \mathrm{E}, 5^{\circ} \mathrm{S}-5^{\circ} \mathrm{N}$, and similarly for SD in March, the area is $50^{\circ}-55^{\circ} \mathrm{N}$ and $60^{\circ}$ $80^{\circ} \mathrm{E}$ which is chosen on the basis of the highest negative correlation region over Eurasia (Fig. 8). However, one must ensure that these five parameters are independent of each other before using them for MLR. Table 1 shows the correlation of these factors with each other. We find that the MSE is highly correlated to SM and V $200 \mathrm{hPa}$ over the Indian region. Therefore, we exclude MSE which ensures that all the used parameters are independent factors and hence the MLR equation can be written as

$M L R P A_{i}=A+B X_{1 i}+C X_{2 i}+D X_{3 i}+E X_{4 i}$,

where MLRPA stands for multiple linear regressed precipitation anomaly, $X_{1}$ is for SM anomaly, $X_{2}$ is for SD anomaly, $X_{3}$ is for $\mathrm{V}$ wind anomaly, and $X_{4}$ is for the precipitation anomaly over EIO for the respective months of MLRPA. $B, C, D, E$ are the corresponding coefficients of
Fig. 11 The scatter plot for the multiple linear regressed precipitation anomaly (MLRPA) with model precipitation anomaly over the Indian region in a June-July and c August-September. b and d Same as $a$ and $c$, but in these cases precipitation over EIO is not considered for calculation of MLRPA. Also indicated is the correlation coefficient between these two precipitation parameters on the top of the panel
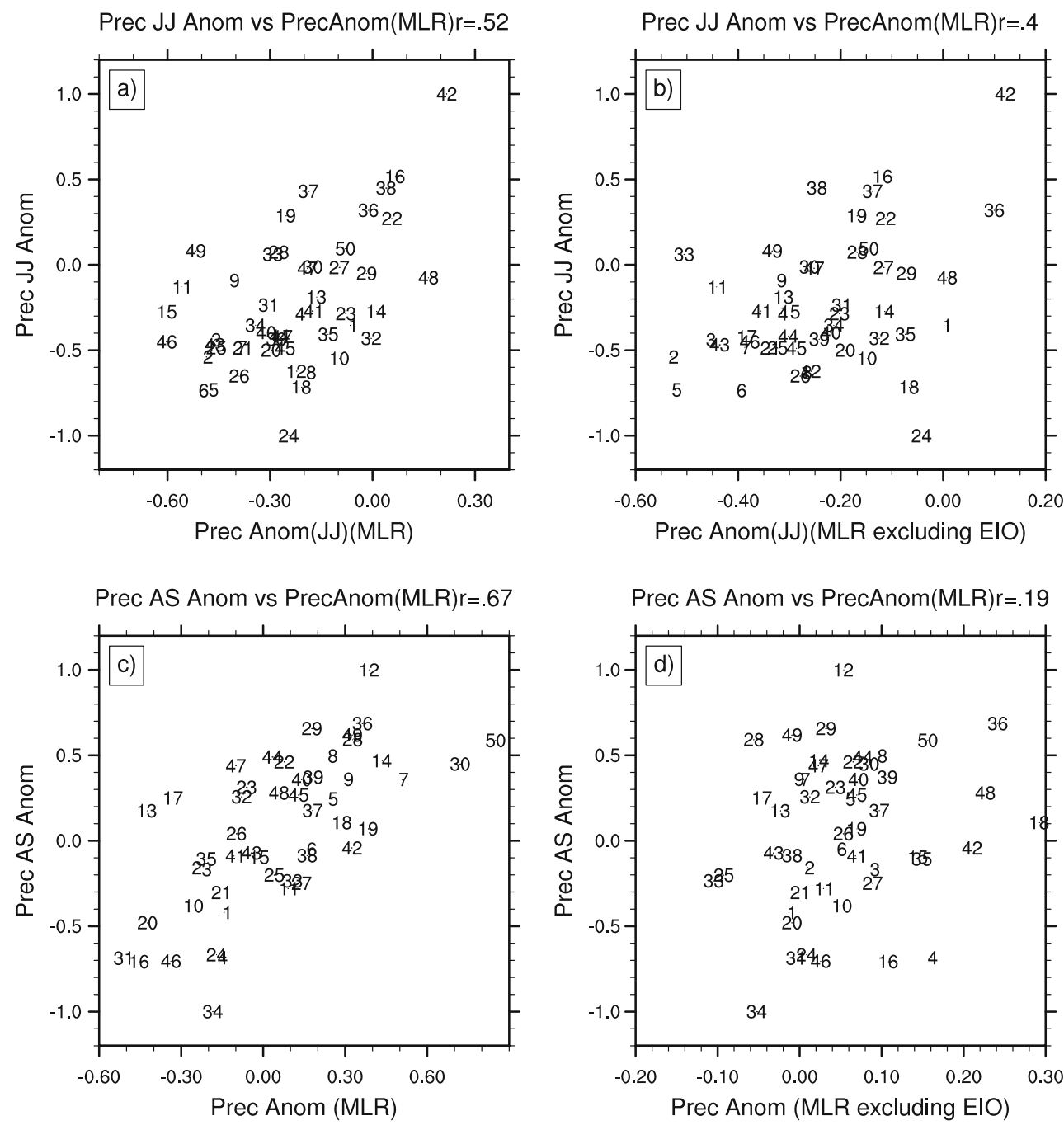
Fig. 12 The scatter plot for the multiple linear regressed precipitation anomaly (MLRPA) with model precipitation anomaly over the Indian region in (a) June-September. (b) Same as $a$ but in this case precipitation over EIO i's not considered for calculation of MLRPA. Also indicated is the correlation coefficient between these two precipitation parameters on the top of the panel

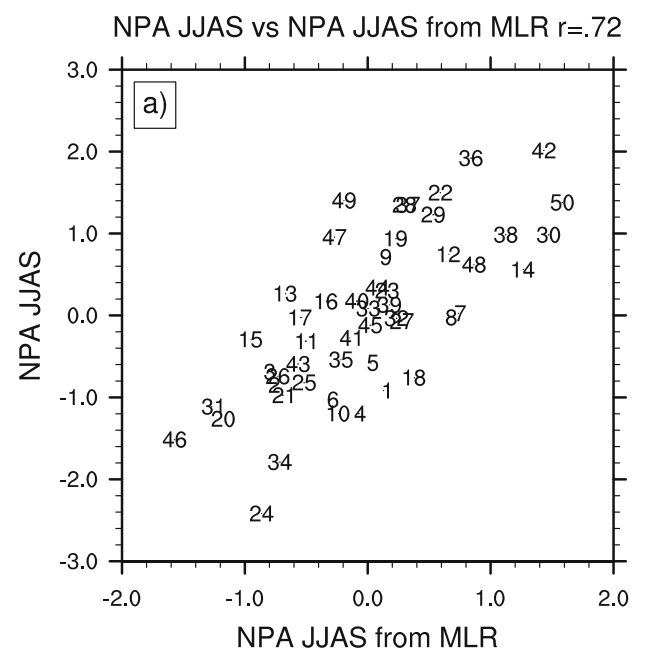

NPA JJAS vs NPA JJAS from MLR $r=.27$

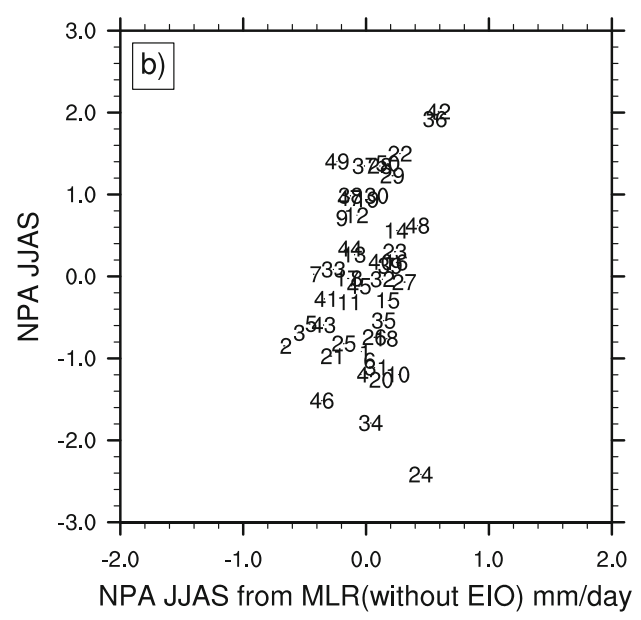

the parameter $X_{1}, X_{2}, X_{3}, X_{4}$. Since all the above mentioned parameters have different units, we have normalized their anomalies by their corresponding standard deviations to get unit less coefficients. $A$ is the constant term which is almost zero while using normalised anomalies. $i$ is the year index which runs from 1 through 50 .

Figure 11a shows the relation between MLRPA and the precipitation anomalies in $\mathrm{JJ}$ over Indian region for 50years of model simulation. The MLRPA is able to explain most of the high anomalous precipitation years in these early months of the summer monsoon over Indian region. The correlation coefficient between these two parameters is 0.52 . Figure $11 \mathrm{~b}$ shows the same but without considering the factor of EIO precipitation anomaly in the MLR calculation. Note that the relationship between MLRPA and the precipitation anomaly in $\mathrm{JJ}$ is weaker in this case $(r=0.40)$ as compared to when precipitation over EIO was considered (Fig. 11a). However, it is evident that there is reasonable association between MLRPA and precipitation anomalies in the early phase of monsoon without the EIO factor. Therefore, there is a considerable role from the precursory factors during this period.

Figure 11c shows the relation of MLRPA with the precipitation anomalies in the later phase of the monsoon (AS) over the Indian region. Over this period, MLRPA explains the extreme precipitation years further better than the earlier phase of the monsoon with a correlation of 0.67 . However, excluding the factor of EIO, the correlation drastically drops down to 0.19 which is much lower than the $\mathrm{JJ}$ period under the same condition. This feature indicates that in the later phase of the monsoon, EIO precipitation see-saw is the most important factor behind the monsoon precipitation variability over the Indian region.

Figure 12a shows the same for the case of JJ and AS together i.e for the whole monsoon period (JJAS). In that case strikingly the correlation becomes 0.72 . From the normalised coefficient values, it can be clearly seen that EIO precipitation is the most impact-full factor throughout the JJAS period (see Table 2). Excluding the EIO factor, the correlation drastically drops down to 0.27 (Fig. 12b). As a whole, the beginning phase is controlled by the EIO and the precursory effects both and the later phase is mostly governed by the EIO only. However, we still need to understand the reason behind this EIO precipitation response to the ISMR.

This EIO precipitation and Indian region monsoon rainfall see-saw are apparently due to the variations in the northward propagation of the convective cloud bands within
Table 2 Multiple linear regression (MLR) coefficient values

\begin{tabular}{lcccc}
\hline Case & B (SM) & C (SD) & D (V) & E (EIO) \\
\hline June-July & 0.04 & -0.11 & -0.33 & -0.35 \\
June-July (without EIO) & 0.07 & -0.12 & -0.29 & NA \\
August-September & -0.04 & 0.03 & -0.08 & -0.67 \\
August-September (without EIO) & 0.12 & 0.04 & -0.02 & NA \\
JJAS & -0.04 & -0.05 & -0.30 & -0.70 \\
JJAS (without EIO) & 0.13 & -0.06 & -0.20 & NA \\
\hline
\end{tabular}


the season, i.e., the Intra Seasonal Oscillation (ISO). The more cloud bands propagate northward towards Indian sub-continent, it rains more over Indian region and less over EIO and hence can create a precipitation see-saw. Figure $13 \mathrm{a}$ and $\mathrm{b}$ is showing the northward propagation on $70^{\circ}-95^{\circ}$ E longitude for two drought years (24 and 46) in the model. It shows lesser north-ward propagation with clear breaks and more elongated breaks over the Indian latitudinal belt with respect to the two flood years (22 and 42) nCC in Fig. 13a and d. In case of drought years, the northward propagation is mainly lesser in the later phase of the monsoon when we see the major impact of the EIO precipitation see-saw. Therefore, the impact of the ISO is stronger in the later phase of the monsoon in the model.

Jiang et al. (2004) proposed a mechanism for the northward propagation of convective cloud bands based on the vertical shear of the zonal wind. Here, we verify that proposed mechanism in terms of flood and drought years of the model. The difference of zonal wind between 200 and
$850 \mathrm{hPa}$ averaged over $70^{\circ}-95^{\circ} \mathrm{E}$ is shown for the JJ, AS, and JJAS period in Fig. 14a, b, and c, respectively. The black line denotes the climatological pattern of the shear in the model. The flood year (red) and the drought year (blue) composites show distinct difference in shear over the latitudinal band $5^{\circ}-25^{\circ} \mathrm{N}$. Figure $14 \mathrm{~d}$, c, and $\mathrm{f}$ shows prominently the difference in wind shear for the flood and drought years when the climatology is removed from the shear for JJ, AS, and JJAS period. During the drought years, the shear is significantly low over the zone where the northward propagation is prominent in the model $\left(10^{\circ}-20^{\circ} \mathrm{N}\right)$. This figure also suggests that the intraseasonal oscillation is more prominent in AS phase of the monsoon.

Figure 15 shows the relation of the zonal wind shear averaged over $5^{\circ}-15^{\circ} \mathrm{N}$ with ISMR. In the model, it shows a strong negative correlation ( $r=-0.53)$ with the zonal wind shear. However, this relationship is weak in observations $(r=-0.18)$. Nevertheless, in case of observed drought years, the relation of the zonal wind shear to ISMR is quite
Fig. 13 The lat-time Hovmoller plot of precipitation averaged over $70^{\circ}-95^{\circ} \mathrm{E}$ in (a) drought year 24; (b) drought year 46; (c) flood years 22; and (d) flood year 42 of the model simulation
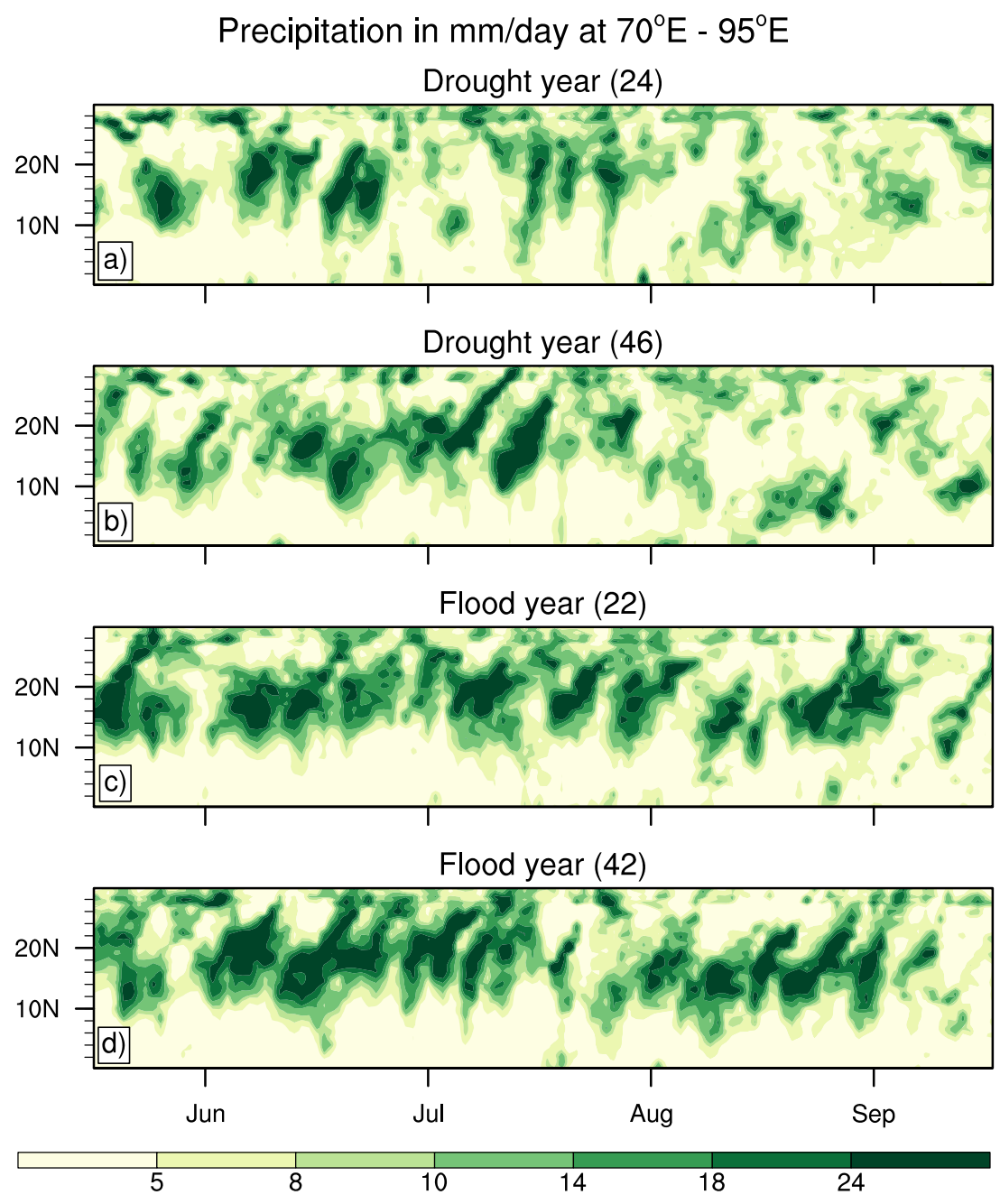


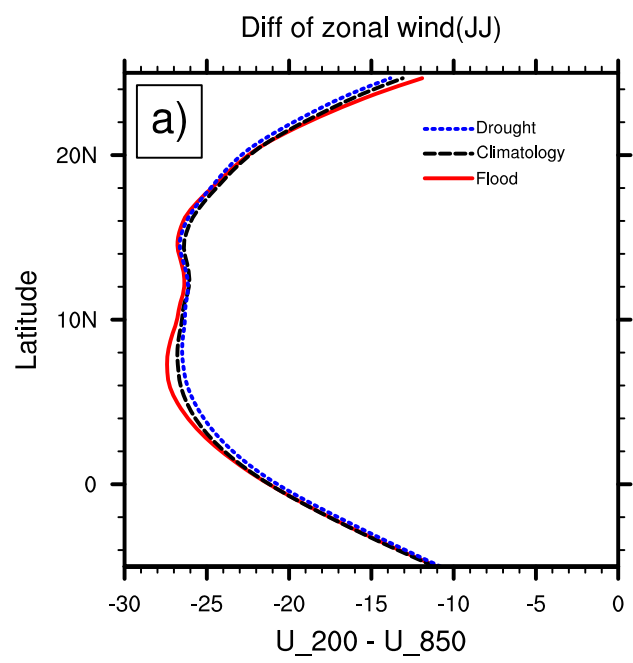

Diff of zonal wind(AS)

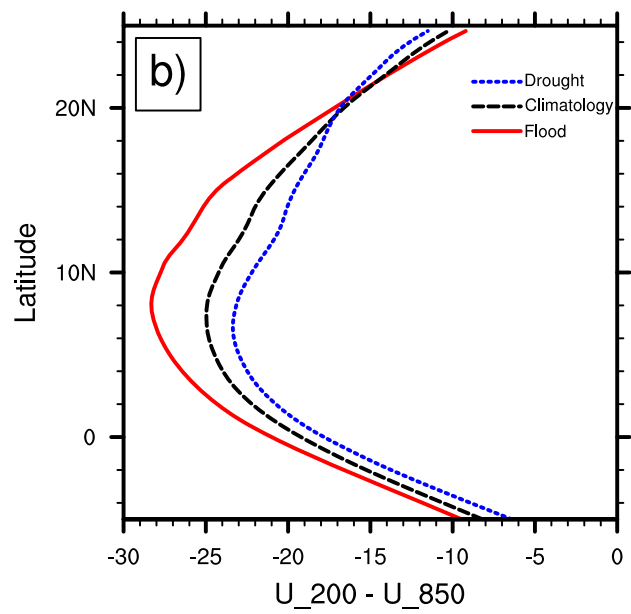

Diff of zonal wind(JJAS)

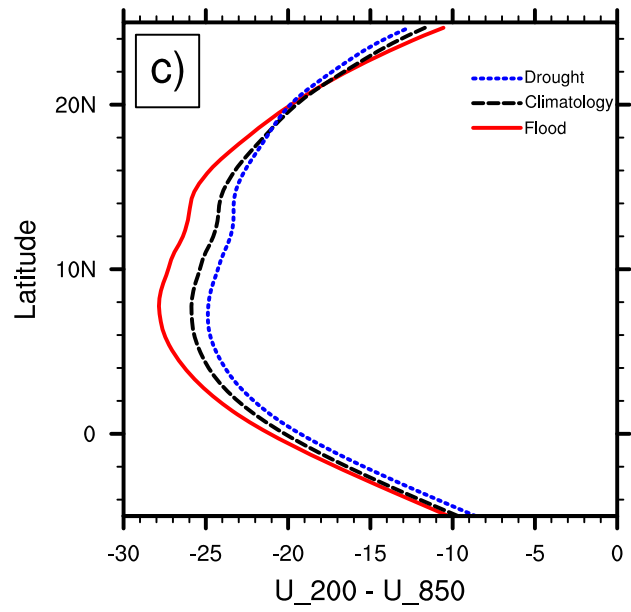

Fig. 14 The composite meridional pattern of the difference in zonal wind between $200 \mathrm{hPa}$ and $850 \mathrm{hPa}$ averaged over $70^{\circ}-95^{\circ} \mathrm{E}$ from climatology (black), flood years (red) and drought years (blue) during (a) June-July; (b) August-September (c) and June-September. b) The difference of the zonal wind shear $\left(\mathrm{U}_{200} \mathrm{hPa}\right.$ minus $\left.\mathrm{U}_{850} \mathrm{hPa}\right)$
Diff from climatology wind shear(JJ)

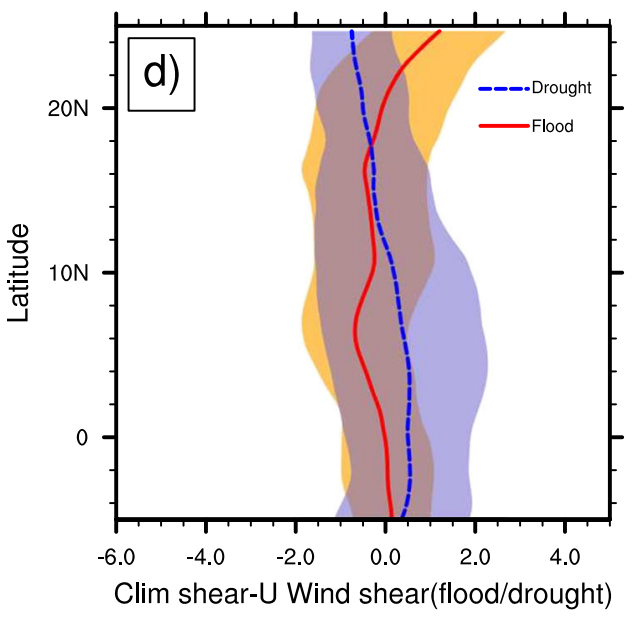

Diff from climatology wind shear(AS)

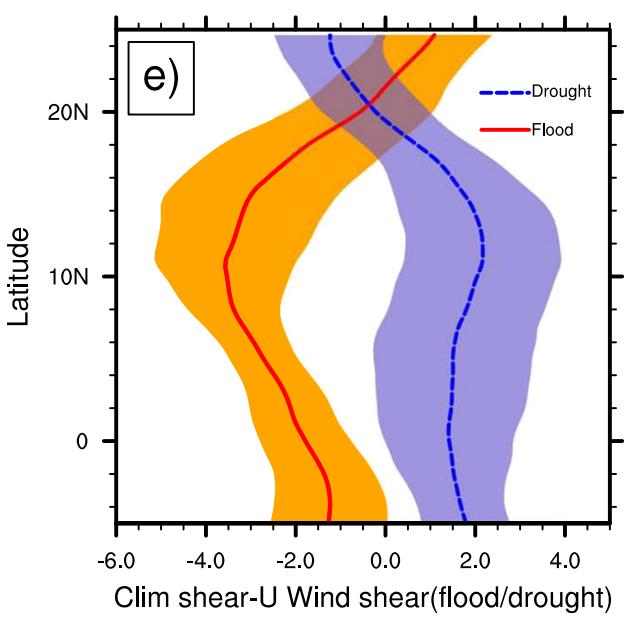

Diff from climatology wind shear(JJAS)

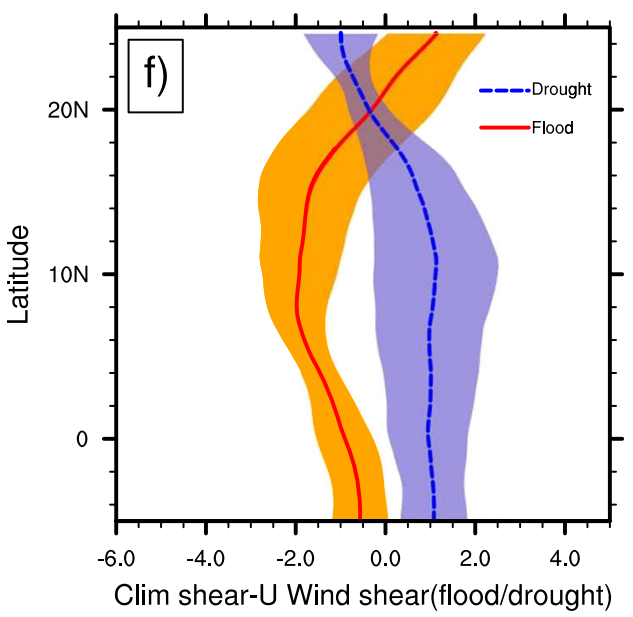

in Flood (Red) and Drought (Blue) years (composite) from the climatology averaged over $70^{\circ}-95^{\circ} \mathrm{E}$ on (d) JJ, (e) AS, (f) JJAS. The orange and the blue shades represent $95 \%$ confidence band on the average shear during flood and drought years respectively 
Fig. 15 The scatter plot of the ISMR anomaly with respect to averaged zonal wind $\left(70^{\circ}-95^{\circ}\right.$ E) shear (U200-U850) from $5^{\circ}-15^{\circ} \mathrm{N}$ for (a) model and (b) from CMAP estimates and ERA40 data

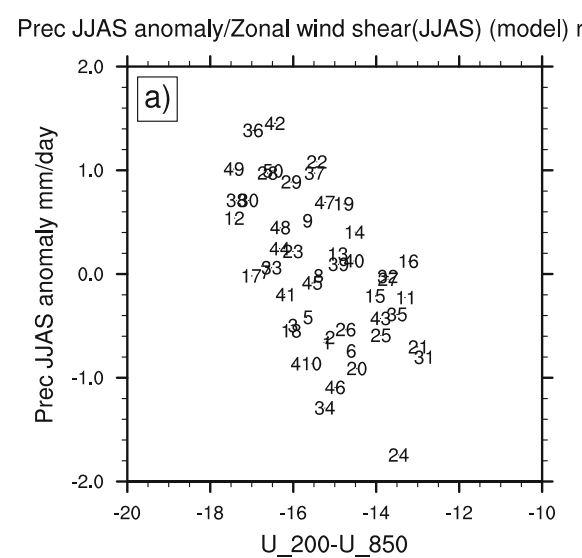

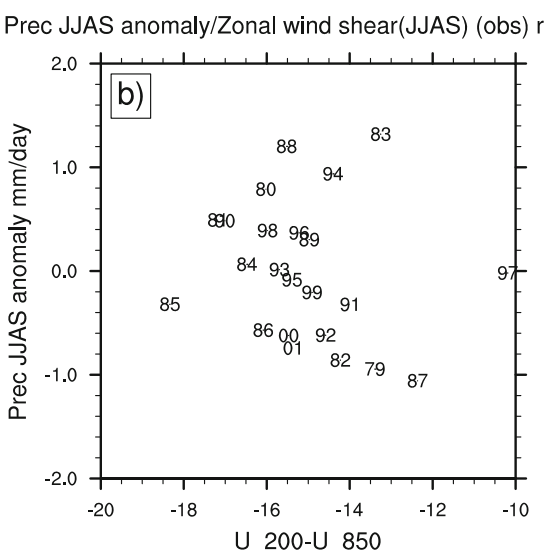

similar to that in the model. The differences occur mainly in case high monsoon rainfall years. It could be due to the absence of the interannual variations in SST in the model and further studies with observed SST forcing might be able to address this aspect in more depth.
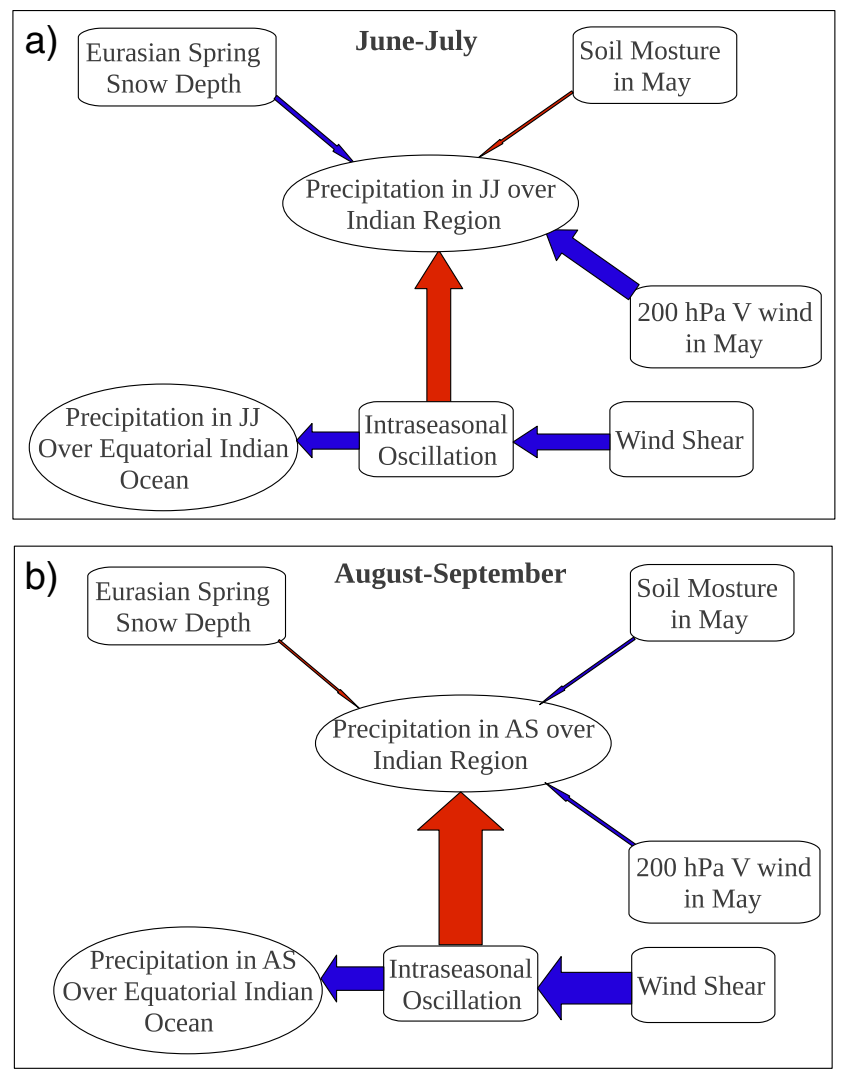

Fig. 16 The schematic diagram showing the mechanisms of interannual variations of precipitation with climatological SST forcing in the model during (a) June-July; and (b) August-September. A positive (negative) correlation between the parameter and precipitation over Indian region is indicated by red (blue) arrow. Width of the arrows show relative strength of the relationship

\section{Summary and conclusions}

We use 50-year long simulation of the CAM4 model with climatological SST forcing to asses the nature of the interannual variations of Indian summer monsoon without the impact of interannually varying SST. The most striking results that came out from this study are summarised as follows:

1. Land-atmosphere conditions determining early (JJ) and late (AS) monsoon intensity are different when SST does not vary interannually.

2. Pre-monsoon (May) surface moist static energy, soil moisture, and phase of upper tropospheric Rossby waves play pivotal role in determining the intensity of precipitation during subsequent June-July. Among those, the upper tropospheric Rossby waves play the biggest role.

3. Low frequency intraseasonal oscillation, arising out of internal dynamics of the system, remains a decisive factor throughout the monsoon season. However, during the early phase of monsoon, their impact is reduced on account of increased role played by Rossby waves, MSE, and soil moisture.

4. The weighted combination of all these parameters explains the interannual variability of monsoon better than any single parameter.

The summary of this study is illustrated in Fig. 16. While, in July-August, precipitation intensity is equally determined by the pre-monsoon $200 \mathrm{hPa}$ Rossby wave phase and intraseasonal oscillations, the August-September monsoon precipitation is primarily a function of the intensity of intraseasonal oscillation (which is linked to vertical shear of zonal wind). Since the intraseasonal oscillation arises due to internal nonlinear dynamics of the atmosphere-ocean system, our results show that predictability of monsoon should be higher during the first half of the season as compared 
to the second half. This is important in terms of real-time prediction of seasonal monsoon precipitation and calls for further studies.

Acknowledgments Open access funding provided by Max Planck Society. R. S. Nanjundiah acknowledges the support from INCOIS (Indian National Centre for Ocean Information Services) under HOOFS (High-resolution Operational Ocean Forecast and reanalysis System) programme for this research. The National Monsoon Mission (NMM) and CTCZ (Continental Tropical Convergence Zone) programme of Ministry of Earth Sciences (MoES) are acnowledged by A. Chakraborty for their financial support. We thank the anonymous reviewer for the constructive comments which enhanced the quality of the paper.

Open Access This article is distributed under the terms of the Creative Commons Attribution 4.0 International License (http:// creativecommons.org/licenses/by/4.0/), which permits unrestricted use, distribution, and reproduction in any medium, provided you give appropriate credit to the original author(s) and the source, provide a link to the Creative Commons license, and indicate if changes were made.

\section{References}

Bamzai AS, Shukla J (1999) Relation between Eurasian snow cover, snow depth, and the Indian summer monsoon: an Observational Study. J Clim 12:3117-3132. doi:10.1175/1520-0442(1999)012< 3117:RBESCS $>2.0 . \mathrm{CO} ; 2$

Barnett TP, Dümenil L, Schlese U, Roeckner E, Latif M (1989) The effect of Eurasian snow cover on regional and global climate variations. J Atmos Sci 46:661-686. doi:10.1175/15200469(1989)046<0661:TEOESC > 2.0.CO;2

Boschat G, Terray P, Masson S (2011) Interannual relationships between Indian Summer Monsoon and Indo-Pacific coupled modes of variability during recent decades. Clim Dyn 37(56):1019-1043. doi:10.1007/s00382-010-0887-y

Boschat G, Terray P, Masson S (2012) Robustness of SST teleconnections and precursory patterns associated with the Indian summer monsoon. Clim Dyn 38(11-12):2143-2165. doi:10.1007/ s00382-011-1100-7

Chakraborty A (2010) The Skill of ECMWF Medium-Range Forecasts during the Year of Tropical Convection 2008. Mon Weather Rev 138(10):3787-3805. doi:10.1175/2010MWR3217.1

Chakraborty A, Nanjundiah RS, Srinivasan J (2006) Theoretical aspects of the onset of Indian summer monsoon from perturbed orography simulations in a GCM. Ann Geophys 24:2075-2089. doi:10.5194/angeo-24-2075-2006

Chakraborty A, Nanjundiah RS, Srinivasan J (2014) Local and remote impacts of direct aerosol forcing on Asian monsoon. Int J Climatol 34(6):2108-2121. doi:10.1002/joc.3826

Douglas GH, Shukla J (1976) An apparent relationship between Eurasian snow cover and Indian monsoon rainfall. J Atmos Sci 33:2461-2462. doi:10.1175/1520-0469(1976)033<2461: AARBES > 2.0.CO;2

Douville H (2002) Influence of soil moisture on the Asian and African monsoons. part ii: Interannual variability. J Clim 15:701-720. doi:10.1175/1520-0442(2002)015<0701:IOSMOT>2.0.CO;2

Douville H, Chauvin F, Broqua H (2001) Influence of soil moisture on the Asian and African monsoons. part i: Mean monsoon and daily precipitation. J Clim 14:2381-2403. doi:10.1175/ 1520-0442(2001)014<2381:IOSMOT>2.0.CO;2
Eltahir EA (1998) A soil moisture-rainfall feedback mechanism 1. Theory and observations. Water Resour Res 34:765-776. doi:10.1029/97WR03499

Fasullo J (2004) A stratified diagnosis of Indian monsoon-Eurasian snow cover relationship. J Clim 17:1110-1122. doi:10.1175/15200442(2004)017<1110:ASDOTI > 2.0.CO;2

Fennessy MJ, Shukla J (1999) Impact of initial soil wetness on seasonal atmospheric prediction. J Clim 12:3167-3180. doi:10.1175/ 1520-0442(1999)012<3167:IOISWO > 2.0.CO;2

Gadgil S, Vinaychandran P, Francis P, Gadgil S (2004) Extremes of the Indian summer monsoon rainfall ,ENSO and equitorial Indian ocean Oscillation. Geophys Res Lett 31:L12,213 1-4. doi:10.1029/2004GL019733

Gadgil S, Rajeevan M, Francis PA (2007) Monsoon variabaility: links to major oscillations over the equitorial Pacific and Indian ocean. Curr Sci 93:182-194

Gent PR, Danabasoglu G, Donner LJ, Holland MM, Hunke EC, Jayne SR, Lawrence DM, Neale RB, Rasch PJ, Vertenstein M, Worley PH, liang Yang Z, Zhang M (2011) The community climate system model version 4. J Clim 24:4973-4991. doi:10.1175/2011JCLI4083.1

Goswami BN (1998) Interannual variations of Indian summer monsoon in a GCM: external conditions versus internal feedbacks. J Clim 11:501-522. doi:10.1175/1520-0442(1998)011< 0501:IVOISM > 2.0.CO;2

Goswami BN, Xavier PK (2005) Dynamics of "internal” interannual variability of the Indian summer monsoon in a GCM. J Geophys Res 110:D24,104 1-17. doi:10.1029/2005JD006042

Hack JJ (1994) Parameterization of moist convection in the National center for Atmospheric Research Community Climate Model (CCM2). J Geophys Res 99:5551-5568. doi:10.1029/93JD03478

Huffman GJ, Adler RF, Bolvin DT, Gu G, Nelkin EJ, Bowman KP, Hong Y, Stocker EF, Wolff DB (2007) The TRMM multisatellite precipitationn analysis (TMPA): quasi-global, multiyear, combined-sensor precipitation estimates at fine scales. J Hydroinformatics 8:38-55. doi:10.1175/JHM560.1

Islam Su, Tang Y, Jackson PL (2013) Asian monsoon simulations by community climate models cam4 and ccsm4. Clim Dyn 41(9):2617-2642. doi:10.1007/s00382-013-1752-6

Jiang X, Li T, Wang B (2004) Structures and mechanism of Northward Propagating Boreal Summer Intraseasonal Oscillation. J Clim 17:1022-1039. doi:10.1175/1520-0442(2004)017<1022: SAMOTN $>2.0 . \mathrm{CO} ; 2$

Joseph PV, Srinivasan J (1999) Rossby waves in May and the Indian summer monsoon rainfall. Tellus 51A:854-864. doi:10.1034/j. 1600-0870.1999.00021.x

Krishnamurti T, Simon A, Thomas A, Mishra A, Sikka D, Niyogi D, Chakraborty A, Li L (2012) Modeling of forecast sensitivity on the march of monsoon isochrones from Kerala to New Delhi, the first 25 days. J Atmos Sci. doi:10.1175/JAS-D-11-0170.1. in press

Krishnan R, Kumar V, Sugi M, Yoshimura J (2009) Internal feedbacks from monsoon-midlatitude interactions during droughts in the Indian Summer Monsoon. J Atmos Sci 66:553-578. doi:10.1175/2008JAS2723.1

Kumar KK, Rajagopalan B, Cane MA (1999) On the weakening relationship between the Indian monsoon and ENSO. Science 284:2156-2159. doi:10.1126/science.284.5423.2156

Kumar KK, Rajagopalan B, Hoerling M, Bates G, Cane M (2006) Unraveling the mystery of Indian monsoon failure during El-niño. Science 314(5796). doi:10.1126/science.1131152

Lawrence DM, Oleson KW, Flanner MG, Thornton PE, Swenson SC, Lawrence PJ, Zeng X, Yang ZL, Levis S, Sakaguchi K, BBonan G, Slater AG (2011a) Parameterization improvements and functional and structural advances in version 4 of 
the Community Land Model. J Adv Model Earth Syst 3:1-28. doi:10.1029/2011MS000045

Lin SJ (2004) A "vertically lagrangian" finite-volume dynamical core for global models. Mon Weather Rev 132:2293-2307. doi:10.1175/1520-0493(2004)132<2293:AVLFDC > 2.0.CO;2

Meehl GA, Arblaster JM, Caron JM, Annamalai H, Jochum M, Chakraborty A, Murtugudde R (2012) Monsoon regimes and processes in CCSM4. Part I: the Asian-Australian monsoon. J Clim 25(8):2583-2608. doi:10.1175/JCLI-D-11-00184.1

Nanjundiah RS (2000) Impact of moisture transport formulation on the simulated tropical rainfall in a general circulation model. Clim Dyn 16:303-317. doi:10.1007/s003820050329

Neale RB, Richter JH, Conley AJ, Park S, Lauritzen PH, Gettelman A, Williamson DL, Rasch PJ, Vavrus SJ, Taylor MA, Collins WD, Zhang M, Lin SJ (2011) Description of the NCAR community atmosphere model (CAM4), Tech. rep. National Center for Atmospheric Research

Neelin JD, Held IM (1987) Modeling tropical convergence based on the moist static energy budget. Mon Weather Rev 115:3-12. doi:10.1175/1520-0493(1987)115<0003:MTCBOT > 2.0.CO;2

Pant GB, Parthasarathy B (1981) Some aspects of an association between the southern oscillation and Indian summer monsoon. Arch Meteorol Geophys Biokl 29:245-251. doi:10.1007/ BF02263246

Peings Y, Douville H (2010) Influence of the Eurasian snow cover on the Indian summer monsoon variability in observed climatologies and CMIP3 simulations. Clim Dyn 34:643-660. doi:10.1007/s00382-009-0565-0

Rai A, Saha SK, Pokhrel S, Sujith K, Halder S (2015) Influence of preonset land atmospheric conditions on the Indian summer monsoon rainfall variability. J Geophys Res Atmos 120(10):4551-4563. doi:10.1002/2015JD023159

Rajagopalan B, Molnar P (2013) Signatures of tibetan plateau heating on Indian summer monsoon rainfall variability. J Geophys Res Atmos 118(3):1170-1178. doi:10.1002/jgrd.50124

Rajeevan M, Bhate J, Kale J, Lal B (2006) High resolution daily gridded rainfall data for the Indian region: Analysis of break and active monsoon spells. Curr Sci 91:296-306

Rasmusson E, Carpenter T (1983) The realtionship between the Eastern Equatorial Pacific Sea Surface Temperature and Rainfall over India and Sri Lanka. Mon Weather Rev 111:3540,384. doi:10.1175/1520-0493(1983)111<0517:TRBEEP>2.0.CO;2

Rayner NA, Parker DE, Horton EB, Folland CK, Alexander LV, Rowell DP (2003) Global analyses of sea surface temperature, sea ice, and night marine air temperature since the late nineteenth century. J Geophys Res 108:ACL 2-1-2-28. doi:10.1029/ 2002JD002670
Saha SK, Halder S, Kumar KK, Goswami B (2010) Pre-onset land surface processes and 'internal' interannual variabilities of the Indian summer monsoon. Clim Dyn 36(11):2077-2089. doi: $10.1007 / \mathrm{s} 00382-010-0886-\mathrm{Z}$

Shukla J, Mintz Y (1982) Influence of Land-Surface Evapotranspiaration on the Earth's Climate. Science 215(4539):1498-1501. doi:10.1126/science.215.4539.1498

Sikka D (1980) Some aspects of the large-scale fluctuations of summer monsoon rainfall over India in realtion to fluctuations in the planetary and regional scale circulations. Proc Indian Acad Sci Earth Planet Sci 89:179-195. doi:10.1007/BF02913749

Terray P, Delecluse P, Labattu S, Terray L (2003) Sea surface temperature associations with the late Indian summer monsoon. Clim Dyn 21(7-8):593-618. doi:10.1007/s00382-003-0354-0

Uppala SM, Kllberg PW, Simmons AJ, Andrae U, Bechtold VDC, Fiorino M, Gibson JK, Haseler J, Hernandez A, Kelly GA, Li X, Onogi K, Saarinen S, Sokka N, Allan RP, Andersson E, Arpe K, Balmaseda MA, Beljaars ACM, Berg LVD, Bidlot J, Bormann N, Caires S, Chevallier F, Dethof A, Dragosavac M, Fisher M, Fuentes M, Hagemann S, Hlm E, Hoskins BJ, Isaksena L, Janssen PAEM, Jenne R, Mcnally AP, Mahfouf JF, Morcrette J, Rayner NA, Saunders RW, Simon P, Sterl A, Trenberth KE, Untch A, Vasiljevic D, Viterbo P, Woollen J (2005) The ERA-40 re-analysis. Q J R Meteorol Soc 131(612):2961-3012. doi:10.1256/qj.04.176

Vernekar AD, Zhou J (1995) The effect of Eurasian snow cover on the Indian monsoon. J Clim 8:248-266. doi:10.1175/15200442(1995)008<0248:TEOESC $>2.0$. CO;2

Webster PJ, Magana VO, Palmer TN, Shukla J, Tomas R, Yanai M, Yasunari T (1998) Monsoons: processes, predictability and the prospects of prediction. J Geophys Res 103:14,451-14,510. doi:10.1029/97JC02719

Xie P, Arkin PA (1996) Analyses of global monthly precipitation using gauge observations, satellite estimates, and numerical model predictions. J Clim 9:840-858. doi:10.1175/1520-0442 (1996)009<0840:AOGMPU>2.0.CO;2

Ye H, Bao Z (2005) Eurasian snow conditions and summer monsoon rainfall over South and Southeast Asia: assesment and comparison. Adv Atmos Sci 22:877-888. doi:10.1007/BF02918687

Zhang GJ (1994) Effects of cumulus convection on the simulated monsoon circulation in a general circulation model. Mon Weather Rev 122:2022-2038. doi:10.1175/1520-0493(1994) $122<2022$ :EOCCOT>2.0.CO;2

Zhang GJ, McFarlane MA (1995) Sensitivity of climate simulations to the parameterization of cumulus convection in the canadian climate centre general circulation model. Atmosphere -ocean 33:407-446. doi:10.1080/07055900.1995.9649539 